Journal of Patient-Centered

\title{
Incorporating Home Visits in a Primary Care Residency Clinic: The Patient and Physician Experience
}

Mary Caitlin St. Clair

Jessica J. F. Kram

Glenda Sundberg

Follow this and additional works at: https://aah.org/jpcrr

Part of the Educational Methods Commons, Family Medicine Commons, Family Practice Nursing Commons, Interprofessional Education Commons, Medical Humanities Commons, Other Education Commons, Patient Safety Commons, Primary Care Commons, and the Public Health and Community Nursing Commons

\section{Recommended Citation}

St Clair MC, Sundberg G, Kram JJ. Incorporating home visits in a primary care residency clinic: the patient and physician experience. J Patient Cent Res Rev. 2019;6:203-9. doi: 10.17294/2330-0698.1701

Published quarterly by Midwest-based health system Advocate Aurora Health and indexed in PubMed Central, the Journal of Patient-Centered Research and Reviews (JPCRR) is an open access, peer-reviewed medical journal focused on disseminating scholarly works devoted to improving patient-centered care practices, health outcomes, and the patient experience. 


\title{
Incorporating Home Visits in a Primary Care Residency Clinic: The Patient and Physician Experience
}

\author{
Mary Caitlin St. Clair, DO, ${ }^{1}$ Glenda Sundberg, FNP-CS, ${ }^{2,3,4}$ Jessica J. F. Kram, MPH ${ }^{3,4,5}$ \\ ${ }^{1}$ Aurora Family Medicine Residency Program, Aurora Health Care, Milwaukee, WI; ${ }^{2}$ Family Practice Center, Aurora St. \\ Luke's Medical Center, Aurora Health Care, Milwaukee, WI; ${ }^{3}$ Department of Family Medicine, Aurora UW Medical Group, \\ Aurora Health Care, Milwaukee, Wl; ${ }^{4}$ Department of Family Medicine and Community Health, University of Wisconsin \\ School of Medicine and Public Health, Madison, WI; ${ }^{5}$ Center for Urban Population Health, Milwaukee, WI
}

\begin{abstract}
Purpose Home visits, once a popular but now uncommon form of health care delivery, are on the rise. Few studies have focused on the value the experience brings to resident physicians and their patients.

Methods

A 6-month pilot was conducted with 11 residents who participated in 32 home visits with 11 patients. Patient and resident experiences were captured through a survey following the home visits.

Results

In all, $100 \%$ of patients and a majority of residents were very interested in being a part of and incorporating future home visits, respectively. Every patient in the survey said that the visits resulted in increased trust of their doctor. The top reasons residents regarded home visits as important included: 1) good for patient care, 2) strengthened relationships with patients, and 3) improved understanding of environmental and social factors affecting patients.

Conclusions Our pilot found that home visits were beneficial to both patients and residents and may be a significant part of the future direction of health care. Ultimately, our hope is to better meet patients' needs by incorporating home visits in residency training and making them a more common practice. ( $\mathrm{J}$ Patient Cent Res Rev. 2019;6:203-209.)
\end{abstract}

Keywords home visits; residency; medical education; health care delivery; patient experience

$\mathrm{H}$ Ome visits were a heavily utilized form of health care delivery in the preindustrial United States. ${ }^{1}$ However, the movement towards more hospital-based medicine with advancing technology contributed to a significant decrease in home visits. Even so, a recent review by Schuchman et al suggests home visits, as well as visits to group homes and assisted living facilities, are currently on the rise and have doubled from 1996 to $2016 .^{2}$ With the increase in value-based health care, the pendulum is swinging to shorter hospital stays and more comprehensive

Correspondence: Glenda Sundberg, FNP-CS,

Family Practice Center, 2801 Kinnickinnic River Parkway, \#250, Milwaukee, WI 53215 (glenda.sundberg@aurora.org) outpatient management. There is a need to revive home visits to improve quality of and access to care, especially with aging and vulnerable populations. ${ }^{2,3}$

It has been well documented that home visits provide high quality care, ${ }^{4}$ encourage the practice of good communication and team-based care, ${ }^{4,5}$ improve health outcomes,${ }^{6}$ strengthen physician confidence in working with community agencies, ${ }^{7}$ reach a frail population that is often least likely to benefit from hospitalization, ${ }^{2-5,8}$ eliminate the burden of patient travel, ${ }^{4}$ empower patients and their caregivers, ${ }^{1,89}$ give physicians a better understanding of a patient's environmental and social determinants of health, ${ }^{4,5,8,10,11}$ and provide emotional support for homebound patients. ${ }^{3}$ We believe that home visits are the ultimate example of wholeperson, patient-centered, continuous care - the kind of care that most family physicians strive to provide 
their patients - and a model of care worth introducing to resident physicians as it presents an opportunity to learn all Accreditation Council of Graduate Medical Education (ACGME) core competencies. ${ }^{8,12}$

In this age of training, most primary care residents have little to no exposure to home visits in medical school and residency, ${ }^{5}$ especially since ACGME transitioned away from completion of home visits during residency in $2014 .^{12}$ There are some primary care programs that still regularly incorporate home visits into their core curriculum..$^{4,710,12}$ Even so, while home visits are being conducted during residency, Sairenji et al identified that residents were going out on only 2 to 5 visits by graduation, limiting their exposure to the home visit experience. ${ }^{12}$ Additionally, it was estimated by program directors that only one-third of the residents intended to provide home visits after graduation. ${ }^{12}$

Multiple studies have touched on physicianpatient satisfaction from home visits., ${ }^{4,6,7}$ One study that surveyed initial and recertifying physicians reported there was a desire for graduating residents to have experience with a broader scope of care, including home visits. ${ }^{8,13}$ It is also recognized that home visits add value to residency education and fulfill all 6 ACGME competencies ${ }^{8,12}$ and at least 16 of the 22 Family Medicine Milestone Project subcompetencies. ${ }^{8}$ Despite this, few training programs and studies incorporating home visits have focused on the value of the experience to the resident physician and their patients. Therefore, the purpose of our quality improvement project was to examine which aspects of the home visit experience patients and residents find meaningful as well as whether the experience makes them more likely to participate in home visits in the future.

\section{METHODS}

We conducted a pilot quality improvement study that incorporated home visits through 1 family medicine residency clinic in Milwaukee, Wisconsin. The project was approved as non-human subjects research by the local institutional review board.

Home visits were conducted for a variety of patients of any age, gender, or health problem who presented to our residency clinic over a 6-month period in 2017.
Patients (if 18 years of age or older, or their family member if under 18) who may benefit from a home visit were identified based on resident feedback and recommendations. Following patient identification, the patients (or family member if patient was $<18$ years old) were asked if they would like to voluntarily participate in a home visit(s).

Home visits were done approximately 2 half-days per month with 4 to 5 patients. A faculty family nurse practitioner accompanied the resident-in-training and provided education, which included how to 1) conduct a home visit, 2) assess the patient's home environment and needs, 3) document a home visit in the electronic medical record, and 4) bill for services. Patients (or family member) and residents were voluntarily surveyed about their home visit experience using a survey developed by the nurse practitioner and resident physician (Tables 1 and 2).

Survey data were summarized using basic summary statistics. Common themes in patient and resident responses to the open-ended survey question "Did you find this home visit a valuable experience?" also were identified by the nurse practitioner and resident physician following team review of comments.

\section{RESULTS}

A total of 11 residents participated in 32 home visits to 11 patients. Overall, $100 \%$ of patients expressed that the home visit increased trust in their doctor (Table 1). Additionally, they were very interested in having future home visits, expressing an interest level of 9.7 on a scale of 1-10 (Table 1).

Residents identified that they were interested in incorporating home visits into their future practice, expressing an interest level of 7.9 on the same scale (Table 2). However, residents were not overly confident in their abilities to incorporate home visits into their future practice (level of confidence: 6.8 on scale of 1-10; Table 2).

Common themes identified in patient comments relating to the value of home visits included improved access and the strengthening of patient/resident relationships (Table 3). One patient commented on the caring energy they felt from the doctors, and another patient alluded 
Table 1. Patient $(N=11)$ Survey Questions and Responses

\begin{tabular}{|c|c|c|}
\hline Question & Scale & $\begin{array}{l}\text { Response, } \\
\text { Mean (SD) }\end{array}$ \\
\hline How interested are you in having a home visit in the future? & 1 [not interested] - 10 [very interested] & $9.7(0.6)$ \\
\hline \multicolumn{3}{|l|}{$\begin{array}{l}\text { Rate how important the following factors are in your } \\
\text { decision to participate in home visits in the future: }\end{array}$} \\
\hline Pace of the visit & 1 [unimportant] - 4 [very important] & $3.9(0.3)$ \\
\hline Good for my medical care & 1 [unimportant] - 4 [very important] & $3.9(0.3)$ \\
\hline Increase my satisfaction with my medical care & 1 [unimportant] - 4 [very important] & $3.9(0.3)$ \\
\hline Improve my doctor's understanding of my environment & 1 [unimportant] - 4 [very important] & $3.9(0.3)$ \\
\hline Better address the goals of my medical care* & 1 [unimportant] - 4 [very important] & $3.9(0.3)$ \\
\hline Strengthen the relationship with my doctor & 1 [unimportant] - 4 [very important] & $3.9(0.3)$ \\
\hline Did this home visit increase trust in your doctor? & Yes/No & Yes: $100 \%$ \\
\hline Did you find this home visit a valuable experience? & Yes/No & Yes: $100 \%$ \\
\hline
\end{tabular}

${ }^{*}$ Responses were available for $n=10$.

$S D$, standard deviation.

to how increased trust with their doctor changed their engagement in their own medical care. A common theme identified in resident comments centered around the idea that home visits were beneficial to understanding a holistic view of the patient.

Ultimately, $100 \%$ of patients and residents identified that they found home visits to be a valuable experience (Tables 1 and 2).

\section{DISCUSSION}

In this pilot study, we aimed to examine what aspects of the home visit experience patients and residents found meaningful. We also sought to determine whether the experience would encourage patients to be a part of, and residents to participate, in future home visits. Our study found that $100 \%$ of patients expressed interest in a home visit in the future, with the majority of residents stating that they were likely to incorporate home visits in their future practice.

Residents in our study recognized that their patient's environment cannot be accurately painted in the conventional office or hospital setting. The majority felt that the experience gave them better insight into patient barriers to care and that the visits provided a new angle to understand the role of social and environmental factors on patient health. This finding mirrors results from previous reports, such as Tschudy and colleagues' prospective mixed-methods cohort study of 50 residents serving as primary care physicians, which found that following the home visit experience, residents identified that they had a better understanding of their patients' home environment and expressed that home visits changed how they treated their patients. ${ }^{10}$ Similarly, Perkel et al described one family practice residency program's experience with a home visit program, highlighting that residents felt that there is always something to gain from a home visit and that the visits helped them understand patients' home environments and the patients themselves. ${ }^{11}$ Additionally, a 2-year house call curriculum implemented by Hayashi et al in an internal medicine residency program emphasized that home visits allow residents to understand a patient's life outside of the conventional office or hospital setting, and such an understanding may help to determine what medical interventions and tests are most feasible for the patient. ${ }^{4}$ Moreover, the authors' more recent study further emphasized that home visit exposure allows for selfreflection and reconnection with humanism. ${ }^{8}$ Lastly, Sairenje et al also supported our findings, identifying that home visits bring to light "a more comprehensive view of the social determinants of health" our patients face and are affected by. ${ }^{12}$ 
Table 2. Resident $(\mathrm{N}=11)$ Survey Questions and Responses

\begin{tabular}{|c|c|c|}
\hline Question & Scale & $\begin{array}{l}\text { Response, } \\
\text { Mean (SD) }\end{array}$ \\
\hline $\begin{array}{l}\text { How interested are you in incorporating home visits into } \\
\text { your future practice? }\end{array}$ & 1 [not interested] - 10 [very interested] & $7.9(1.6)$ \\
\hline $\begin{array}{l}\text { How confident are you in incorporating home visits into } \\
\text { your future practice? }\end{array}$ & 1 [not confident] - 10 [very confident] & $6.8(1.5)$ \\
\hline \multicolumn{3}{|l|}{$\begin{array}{l}\text { Rate how important the following factors are to your interest } \\
\text { in conducting home visits in your future practice: }\end{array}$} \\
\hline Pace of day & 1 [unimportant] - 4 [very important] & $3.2(0.4)$ \\
\hline Good for patient care & 1 [unimportant] - 4 [very important] & $4.0(0.0)$ \\
\hline Increase job satisfaction & 1 [unimportant] - 4 [very important] & $3.5(0.7)$ \\
\hline $\begin{array}{l}\text { Improve understanding of environmental/social factors } \\
\text { affecting patients }\end{array}$ & 1 [unimportant] - 4 [very important] & $3.7(0.5)$ \\
\hline Better address patients' goals of care & 1 [unimportant] - 4 [very important] & $3.5(0.7)$ \\
\hline Strengthen the relationship with patients & 1 [unimportant] - 4 [very important] & $3.8(0.4)$ \\
\hline Did you find this home visit a valuable experience? & Yes/No & Yes: $100 \%$ \\
\hline
\end{tabular}

$S D$, standard deviation.

In our study, residents noted that working in the patient's own environment led to stronger, more trusting doctor-patient relationships. This was reinforced by responses from patients, every one of whom felt that their home visit experience increased their trust in their doctor. One patient commented on becoming more engaged in their medical care as a result of the home visit. Similarly, a systematic review conducted by Abbott and colleagues discussed how home visit programs empower patients to maintain their health and manage existing conditions. ${ }^{9}$ In addition to empowering patients, home visit programs can empower patient caregivers, with caregivers feeling more informed about the patients' medical needs following the visit. ${ }^{1}$ Ultimately, we believe that both patients and residents value how the home visit encourages patient-physician engagement and fosters a more patient-centered plan. Such relationships and plans are likely to increase patient satisfaction ${ }^{6,7}$ as well as physician satisfaction. ${ }^{4,6}$

Training residents with the skills to perform home visits during residency may boost resident confidence to incorporate home visits in future practice. Based on the results of our study, residents lack confidence in incorporating home visits into future practice or feel that they may not have the skills necessary to incorporate such visits. Hayashi et al found that introduction of a home visit curriculum improved residents skills, attitudes, and knowledge for incorporating such visits into practice. ${ }^{4}$ Similarly, the University of Tokyo recently began requiring a 2-week home medical care clerkship for sixth-year medical students; based on questionnaire scoring of 103 students, attitudes toward home care grew more positive after the rotation. ${ }^{14}$ Given the potential benefits to home visit training and exposure, it should be incorporated into residency training programs, ${ }^{4,7,10}$ especially because there is interest from residents on having home visits incorporated into their curriculum. ${ }^{10}$ This interest should be met with enthusiasm from residency programs given that it meets ACGME core competencies and milestones. ${ }^{8,12}$

Furthermore, we need to realign or shift training based on patient need, and there is a need to increase home visits in our practices for the ever-growing vulnerable and elderly populations. ${ }^{2-5}$ Authors of the Tokyo study concluded that establishing home medical care practice was essential to accomplishing the Japanese government's aim of developing an integrated care system that allows the country's rising 
Table 3. Open-Ended Survey Comments

\begin{tabular}{|c|c|}
\hline \multicolumn{2}{|l|}{ Patients* } \\
\hline Theme: Environment & "I was able to show how my environment affects my life." \\
\hline Theme: Access & $\begin{array}{l}\text { "In winter, I prefer [my doctor] to come here. It's a lot harder for me to come in [to the clinic visit]." } \\
\text { "I can't leave my home, so I love that they are able to come to me." } \\
\text { "I get continuous care." } \\
\text { "They take care of my wife and I. She has Alzheimer's [disease] and we can't get in to see } \\
\text { them, so they come to us. I am very grateful." }\end{array}$ \\
\hline Theme: Trust & $\begin{array}{l}\text { "I used to lie a lot [before the home visits]." } \\
\text { "I wasn't sure how this would go, but they were very friendly and helped me with a lot of things." } \\
\text { "You were cool to talk to." }\end{array}$ \\
\hline $\begin{array}{l}\text { Theme: Strengthening } \\
\text { relationship }\end{array}$ & $\begin{array}{l}\text { "You show you care." } \\
\text { "They helped me, I'm glad they came." } \\
\text { "It was so nice they came to see me. I love my doctor." } \\
\text { "They cared. I'm so happy." }\end{array}$ \\
\hline Theme: Empowering & "I know better what my health is and how to take care of it." \\
\hline Residents* & \\
\hline $\begin{array}{l}\text { Theme: Holistic patient } \\
\text { picture }\end{array}$ & $\begin{array}{l}\text { "I felt this experience really shows you the full patient experience. Especially in my patient who } \\
\text { I was struggling to understand how to help." }\end{array}$ \\
\hline Theme: Feasibility & "I am uncertain, however, how feasible this will be for the established practice I am joining." \\
\hline Theme: Environment & $\begin{array}{l}\text { "Yes, social situation greatly affects health by being a barrier or support." } \\
\text { "This was an extremely valuable experience that, more than anything, helped me to } \\
\text { understand the social and environmental context of patient care." } \\
\text { "It gave me very good insight into the home and social environment that my patients are } \\
\text { coming from." } \\
\text { "It gives you a better idea of what makes people tick, what [is] most important to them, how } \\
\text { they lead their lives." } \\
\text { "It takes away the sterile white coat experience, empowering patients in their own environment } \\
\text { to be truly in control of their own health care." }\end{array}$ \\
\hline Theme: Access & $\begin{array}{l}\text { "Through eliminating harried travel and waiting rooms, both of which can be traumatic } \\
\text { experiences, home visits put everyone on an even playing field. They take away the barriers } \\
\text { that past traumas, health status, mobility, travel, and time pose to access to quality care." } \\
\text { "I felt getting a patient's perspective on their home life is important. Furthermore, understanding } \\
\text { the social factors that inhibit compliance is important to understand as a physician." } \\
\text { "Yes, it allowed me to care for my patient in a unique environment and bring care to individuals } \\
\text { who find it difficult to get into the clinic." }\end{array}$ \\
\hline Theme: Trust & $\begin{array}{l}\text { "Yes, gives a better understanding of patient's barriers to care." } \\
\text { "There is a different energy to the visit, you can feel the increased trust in the physician-patient } \\
\text { relationship." }\end{array}$ \\
\hline $\begin{array}{l}\text { Theme: Strengthening } \\
\text { relationship }\end{array}$ & $\begin{array}{l}\text { "Extremely valuable - from our perspective as family practitioners, we have a glimpse into our } \\
\text { patient's lives. It strengthens our relationships and lets them know that we care for them." } \\
\text { "Also helps rapport" }\end{array}$ \\
\hline $\begin{array}{l}\text { Theme: Increase job } \\
\text { satisfaction }\end{array}$ & $\begin{array}{l}\text { "I would love to be able to do this again in the future." } \\
\text { "Home visits are a refreshing experience compared to the usual clinic/hospital experience, they } \\
\text { help remind you of why you became a doctor." }\end{array}$ \\
\hline Miscellaneous quotes & $\begin{array}{l}\text { "It is easier to feel a patient's energy in the home. You can better understand how their home } \\
\text { and their energy in the home affects their well-being and health." } \\
\text { "Enjoyed seeing how another provider [the nurse practitioner] works, especially with the } \\
\text { 'challenging' patients. Would love to learn more about the financial side of things to see how it } \\
\text { could be a sustainable part of my future career." }\end{array}$ \\
\hline
\end{tabular}

*Some patient and resident quotes fell into multiple identified themes. 
elderly population, including those with disabilities, to continue living in the community. ${ }^{14}$ Increasing the volume of home visits also will increase the next generation's confidence in conducting home visits. ${ }^{4,5,7}$ Even so, while providing training to residents can increase confidence, residents may not be willing to provide home visits in their future practice. ${ }^{7}$ However, Coutinho et al reported that graduating family medicine residents are more willing to incorporate home visits as part of more comprehensive practice. ${ }^{13}$ It is our hope that by encouraging residents to participate in the home visit experience throughout residency, they will be exposed to positive experiences. These experiences, paired with an increase in confidence in doing the home visits themselves, will perhaps motivate and inspire them to seek this out or start this practice upon graduation.

Our pilot study has strengths and limitations. With limited home visit training in family medicine residency and limited studies to evaluate the topic, our results add to the current literature and further support the need to expose more residents to this once-common practice. While our study demonstrated that both patients and residents expressed interest in conducting home visits, sample size was small and patients and residents were identified at only one clinic site, therefore it is not generalizable. In addition, our patient sample and their responses may have been biased due to self-selection, as we selected those who were in need of and would benefit most from having a home visit. Lastly, while we identified that residents lack confidence in incorporating home visits in future practice, we did not identify specific concerns or perceptions (time constraints, reimbursement, home visit scope including patient and visit type, lack of diagnostic capabilities, etc) that could be addressed to boost confidence. A recent study did identify that the top three barriers to resident home visit education were scheduling difficulties, resident time, and faculty time. ${ }^{12}$ These barriers may impact a resident's confidence in incorporating home visits into future practice and potentially could be addressed within residency programs. Despite these limitations, we believe this pilot captured the voice of both patients and residents regarding the home visit experience.

\section{CONCLUSIONS}

Findings suggest the importance of incorporating home visits into residency education and primary care practice. Residency programs will need to create a curriculum that gives residents the framework and skills to boost their confidence in providing home visits in their respective practices. Ultimately, home visits are powerful, and their future benefits should not be underestimated. They should be a permanent part of the curriculum and supported by administrators and hospital systems. Through incorporating home visits into practice, residents have the potential to change the landscape of health care delivery.

\section{Patient-Friendly Recap}

- Home medical visits to patients with serious health problems or mobility issues may provide health and cost benefits.

- The authors piloted a quality improvement project in which physicians-in-training were exposed to the home visit experience under guidance of a faculty nurse practitioner.

- After 6 months, surveys revealed that participating patients and residents both expressed strong interest in future home visits and that the experience increased residents' confidence in providing home visits.

\section{Acknowledgments}

The authors thank Konrad de Grandville, MD, of Aurora Health Care for project oversight and support.

\section{Author Contributions}

Study design: all authors. Data acquisition or analysis: all authors. Manuscript drafting: all authors. Critical revision: all authors.

\section{Conflicts of Interest}

None.

\section{References}

1. Muramatsu N, Mensah E, Cornwell T. A physician house call program for the homebound. Jt Comm J Qual Saf. 2004;30:266-76. CrossRef

2. Schuchman M, Fain M, Cornwell T. The resurgence of homebased primary care models in the United States. Geriatrics (Basel). 2018;3(3):E41. CrossRef

3. Philbrick JT, Connelly JE, Corbett EC Jr. Home visits in a rural office practice: clinical spectrum and effect on utilization of health services. J Gen Intern Med. 1992;7:522-7. CrossRef

4. Hayashi J, Christmas C, Durso SC. Educational outcomes from a novel house call curriculum for internal medicine residents: report of a 3-year experience. J Am Geriatr Soc. 2011;59:1340-9. CrossRef 
5. McGregor MJ, Sloan J. Realigning training with need: a case for mandatory family medicine resident experience in community-based care of the frail elderly. Can Fam Physician. 2014;60:697-9.

6. Hughes SL, Weaver FM, Giobbie-Hurder A, et al. Effectiveness of team-managed home-based primary care: a randomized multicenter trial. JAMA. 2000;284:2877-85. CrossRef

7. Jakubovicz D, Srivastava A. Home visits in family medicine residency: evaluation of 8 years of a training program. Can Fam Physician. 2015;61:e189-95.

8. Hayashi J, Christmas C. House calls and the ACGME competencies. Teach Learn Med. 2009;21:140-7. CrossRef

9. Abbott LS, Elliott LT. Eliminating health disparities through action on the social determinants of health: a systematic review of home visiting in the United States, 2005-2015. Public Health Nurs. 2016;34:2-30. CrossRef

10. Tschudy MM, Platt RE, Serwint JR. Extending the medical home into the community: a newborn home visitation program for pediatric residents. Acad Pediatr. 2013;13:443-50. $\underline{\text { CrossRef }}$
11. Perkel RL, Kairys MZ, Diamond JJ, et al. Eleven years of house calls: a description of a family practice residency program's experience from 1981-1992 with an urban home visit program for the elderly. J Long Term Home Health Care. 1994;13(4):13-26.

12. Sairenji T, Wilson SA, D'Amico F, Peterson LE. Training family medicine residents to perform home visits: a CERA survey. J Grad Med Educ. 2017;9:90-6. CrossRef

13. Coutinho AJ, Cochrane A, Stelter K, Phillips RL Jr, Peterson LE. Comparison of intended scope of practice for family medicine residents with reported scope of practice among practicing family physicians. JAMA. 2015;314:2364-2372. CrossRef

14. Yamanaka T, Hirota Y, Noguchi-Watanabe M, et al. Changes in attitude of medical students toward home care during a required 2-week home care clinical clerkship program. Geriatr Gerontol Int. 2018;18:655-6. CrossRef

(C) 2019 Aurora Health Care, Inc. 